\title{
Berichtigungen zu Band IX
}

1. P. Thullen, Soziale Rentensysteme in relativen Beharrungszuständen. Auf Seite 244 ist die Formel (7) zu ersetzen durch

$$
\left[\mathrm{V}_{1}(\mathrm{t})-\mathrm{V}_{2}(\mathrm{t})\right](\delta-\tilde{\varrho})=\mathrm{S}(\mathrm{t})\left(\pi_{2}-\pi_{1}\right)
$$

2. J. Heinau, Weitere Beobachtungen über die Sterblichkeit abgelehnter Risiken in der Lebensversicherung.

In Tabelle 7 auf Seite 438 ist in den Spalten unter $A_{3}$ die 6 . Zeile zu ersetzen durch die Zahlen

$$
\begin{array}{lll}
125 & 74 & 193
\end{array}
$$

und die 9. Zeile zu ersetzen durch

$$
108 \quad 65 \quad 160 .
$$

Diese Änderungen wirken sich auch auf die Abb. 2, Gruppe A, 3. Beobachtungsjahrfünft aus.

Auf Seite 442, 16. Zeile von oben, ist „, $\mathrm{A}_{3}-\mathrm{S}$ und“ zu streichen. 